\title{
The Impact of Healthcare Accreditation on Patients' Satisfaction: A Literature Review
}

\author{
Gazala Khan \\ Director, Indira Institute of Management Sciences, \\ Sahayog Educational Campus, \\ Vishnupuri, Nanded-431 606 \\ Maharashtra State, India \\ Email: gazala_shaikh59@yahoo.com
}

Area/Section: Health Sciences.

Type of the Paper: Review.

Type of Review: Peer Reviewed as per $\underline{\mathrm{C}}|\mathrm{O}| \mathrm{P}|\mathrm{E}|$ guidance.

Indexed in: OpenAIRE.

DOI: http://doi.org/10.5281/zenodo.3862791.

Google Scholar Citation: $\underline{\text { IJHSP }}$

How to Cite this Paper:

Gazala Khan (2020). The Impact of Healthcare Accreditation on Patients' Satisfaction: A Literature Review. International Journal of Health Sciences and Pharmacy (IJHSP), 4(1), 4956. DOI: http://doi.org/10.5281/zenodo.3862791.

International Journal of Health Sciences and Pharmacy (IJHSP)

A Refereed International Journal of Srinivas University, India.

(C) With Author.

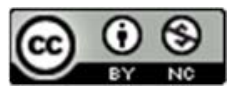

This work is licensed under a Creative Commons Attribution Non-Commercial 4.0 International License subject to proper citation to the publication source of the work.

Disclaimer: The scholarly papers as reviewed and published by the Srinivas Publications (S.P.), India are the views and opinions of their respective authors and are not the views or opinions of the SP. The SP disclaims of any harm or loss caused due to the published content to any party. 


\title{
The Impact of Healthcare Accreditation on Patients' Satisfaction: A Literature Review
}

\author{
Gazala Khan \\ Director, Indira Institute of Management Sciences, \\ Sahayog Educational Campus, \\ Vishnupuri, Nanded-431 606 \\ Maharashtra State, India \\ Email:gazala_shaikh59@yahoo.com
}

\begin{abstract}
Patient satisfaction had been the center of many research studies globally. However, very few studies published had analyzed the impact of healthcare accreditation on patients' satisfaction. Objective: To review and analyze the impact of hospital accreditation on patients' satisfaction. Method: A comprehensive searches were conducted in the online databases of goggle scholars and research gate. Results: This review revealed that the hospital accreditation impacted on patients' satisfaction in several departments. Conclusions: The hospital accreditation has a positive impact on patients' satisfaction in several departments.
\end{abstract}

Keywords: Accreditation, Hospital, Impact of accreditation, Patients' satisfaction, patients' experience.

\section{INTRODUCTION :}

Quality has become a fundamental requirement for healthcare organizations in order to survive and succeed in the competitive, demanding and challenging healthcare service industry. Total Quality Management (TQM) is considered to be an essential way to achieve the required excellence in business practice, as it provides customer satisfaction through continuous quality improvement.

In this modern era of science, technology and quality, the healthcare service industry is a thriving sector, which is continuously on high demand in all the continents of the world.

Accreditation of a health care organization is an external evaluation of the level of compliance against a set of organizational standards (Bohigas et al, 1998) [1]. The United States (US) American College of Surgeons (ACS), first developed quality standards for hospitals \& other health care facilities and introduced the "Minimum Standard for Hospitals" in 1917. Increased world trade in manufactured goods after World War II, leads to the creation of the Geneva, Switzerland based International Standards Organization (ISO) in 1947. In 1951 the Joint Commission on Accreditation of Healthcare Organizations (JCAHO) was formed in the United States (Montagu D.
London) [2]. This concept was exported to Canada and Australia in the 1960s and 1970s and reached Europe in the 1980s. Accreditation programs spread all over the world in the 1990s (Shaw CD, 2000) [3].

\section{REVIEW OF LITERATURE :}

The healthcare accreditation is usually a voluntary program, sponsored by a NonGovernmental Organization (NGO), in which educated, experienced and trained personnel evaluate the compliance of a health care organization with pre-established performance standards (Shaw CD, 2004) [4].

Structure, process and outcome can be improved by implementing the healthcare accreditation standards as they are based on current evidence based practices and processes. The accrediting organizations assert that their methodologies are effective and efficient in improving the structure, process, outcome and maintaining the quality of the healthcare industry.

The increased international focus on improving patient outcomes, safety and quality of care has led stakeholders, policy makers and healthcare provider organizations adopt standardized processes for evaluating health care organizations (Brubakk et al., 2015) [5].

2.1 History of Patient Satisfaction: 
The concept of Patient Satisfaction exists since 1960's but in late 1970's and late 1980's only active research was initiated on this subject and it replaced the idea of "Quantity of Life" by "Patient Centered Concept called "Quality of Life" (Ekram S, Rahman, 2006) [6].

Parasuraman et al. $(1985,1988)$ [7] undertook a series of research projects which gave birth to the service quality model "SERVQUAL". The SERVQUAL approach begins with the assumption that service quality (Parasuraman et al. 1985) [8]. Initially the "SERVQUAL" was used as a tool to measure the "Patient Satisfaction" in the healthcare service industry. The concept of "Patient Satisfaction" was ignored despite of its importance in healthcare service industry. The Press Ganey Company was started in 1985 by two Notre Dame Professors, Irwin Press (a medical anthropologist) and Rod Ganey (a sociologist and statistician) who created a new market by applying reliable survey design and administration to healthcare industry. With their surveys on "Patient Satisfaction", they realized the healthcare providers, the importance of patients' levels of satisfaction with the care they received. Ultimately, the curiosity in and efforts towards improving patient satisfaction caught the consideration of the federal government and led to the first federally-backed survey of patient satisfaction, called Hospital Consumer Assessment of Healthcare Providers and Systems (HCAHPS) survey.

$\begin{aligned} & \text { 2.2 Hospital Consumer Assessment of } \\ & \text { Healthcare Providers and Systems } \\ & \text { (HCAHPS): }\end{aligned}$
PCAHP

In the year 2002, the Centers for Medicare and Medicaid Services (CMS) and the Agency for Healthcare Research and Quality (AHRQ) worked together to research develop, and test the HCAHP Ssurvey and the implementation began in October of 2006 and in March 2008 the first public score reports issued.

The HCAHPS survey is usually conducted randomly for adult inpatients between 48 hours and 6 weeks after discharge. This survey contains 21 (twenty-one) patient perspectives and 9 (nine) key topics.

1. Communication with doctors

2. Communication with nurses

3. Responsiveness of hospital staff

4. Pain management
5. Communication about medicines

6. Discharge information

7. Cleanliness of the hospital environment

8. Quietness of the hospital environment

9. Transitions of care

2.3 Patient Satisfaction vs. Patient Experience:

"To assess patient experience, one must find out from patients whether something that should happen in a health care setting (such as clear communication with a provider) actually happened or how often it happened" (Agency for Healthcare Research and Quality -AHRQ).

"Satisfaction is about whether a patient's expectations about a health encounter were met. Two people who receive the exact same care, but who have different expectations for how that care is supposed to be delivered, can give different satisfaction ratings because of their different expectations" (AHRQ).

Doctor-patient relationship plays a vital role in Patients' satisfaction. Moreover, the patients are more satisfied even if there is a longer waiting time but they are well-informed of the necessary procedures in a clinical encounter (Pulia, \& FAAEM, 2011) [9].

2.4 Impact of hospital accreditation on the Patients' Satisfaction:

Researchers had conducted several studies earlier to understand the impact of hospital accreditation on the patients' satisfaction.

"The impact of hospital accreditation on the ambulance services satisfaction paper revealed that there was a positive impact on the patients and families satisfaction that have used the ambulance services after accreditation" (Shaikh, 2016) [10].

"The Impact of Hospital Accreditation on the Patient Satisfaction of Physiotherapy Department Services paper results indicates that there is a positive impact on the patient's satisfaction of Physiotherapy Department Services after accreditation" (Shaikh, 2017) [11].

"The Impact of Hospital Accreditation on the Patients Satisfaction of Dietary Services paper revealed that there is a significant difference between the satisfaction levels of patients on the overall dietary service before and after accreditation. The accreditation has a positive impact on the satisfaction of dietary services of the study hospital" (Shaikh, 2017) [12].

"The Impact of Hospital Accreditation on the 
Patients Satisfaction of Laboratory Department Services results indicate that the mean satisfaction score has improved from before accreditation compared to after accreditation" (Shaikh, 2017) [13].

"The Impact of Hospital Accreditation on the Patients Satisfaction of Emergency Department Services paper revealed that the accreditation has a positive impact on the patient's satisfaction of Emergency Department Services of the study hospital" (Shaikh, 2017) [14].

"The Impact of Hospital Accreditation on the Patient Satisfaction of In-Patient Department Services research paper revealed that there is a significant difference in the satisfaction with respect to the overall experience in the hospital between before accreditation and after accreditation (Shaikh, 2017) [15].

"The Impact of Hospital Accreditation on the Patients Satisfaction of Haemodialysis Department Services paper results indicate that the mean satisfaction score has improved from before accreditation compared to after accreditation" (Shaikh, 2017) [16].

"The Impact of Hospital Accreditation on the Patient Satisfaction of Radiology Department Services paper revealed that the mean satisfaction score has improved from before accreditation compared to after accreditation" (Shaikh, 2017) [17].

"The Impact of Hospital Accreditation on the Patient's Satisfaction of Pharmacy Department Services research paper indicates that the satisfaction score has improved from before accreditation compared to after accreditation which indicates that the accreditation has a positive impact on the satisfaction of the Pharmacy Department Service of the study hospital" (Shaikh, 2017) [18].

"The Impact of Hospital Accreditation on the Patients Satisfaction of Out-Patient Department Services research paper revealed that the satisfaction score has improved from before accreditation compared to after accreditation which indicates that the accreditation has a positive impact on the satisfaction of OutPatient Department Services of the study hospital" (Shaikh, 2017) [19].

2.5 Patient Experience:

Researchers had conducted several studies earlier to understand the impact of hospital accreditation on the patients' experience.
"Impact of National Accreditation on the Patients' Experience of Ambulance Services: A Case Study research paper revealed that the national accreditation NABH has a positive impact on the patients and families who have used the ambulance services" (Shaikh, 2018) [20].

"The Impact of Hospital Accreditation on the Patients' Experience of Hemodialysis Department: A Case Study research paper revealed that the accreditation has a positive impact on the patient's experience of Haemodialysis Department Services of the study hospital" (Shaikh, 2019) [21].

"The Impact of Hospital Accreditation on the Patients' Experience of Emergency Department: A Case Study research paper indicates that the accreditation has a positive impact on the Patients Experience of Emergency Department Services in the study hospital" (Shaikh, 2019) [22].

2.6 Impact of Hospital Accreditation:

Researchers had conducted several studies earlier to understand the impact of hospital accreditation on other services and processes.

"The Impact of Hospital Accreditation on the Completeness of Personnel Files in Human Resource Department research paper revealed that there is a significant difference in the content of the personnel files with regards to General, Credentialing, Orientation, Evaluations, Training and In Service Education, Certificates, Privileges, Licenses, Training and Licensures, Competencies for Nursing and Paramedical Staff and Others between before accreditation and after accreditation. Hence, there is a positive impact of $\mathrm{NABH}$ Accreditation on the completeness of personnel files in the Human Resource Department" (Shaikh, 2017) [23].

"The Impact of Hospital Accreditation on the Number of Occurrence Variance Report or Incident Reports research paper revealed that there is a significant difference in the mean occurrence variance report between before accreditation and after accreditation" (Shaikh, 2018) [24].

"A Comparative Study on Laboratory and Blood Bank Performance by Using the Quality Indicators research paper revealed that the mean rating of the second half is better than the mean rating of the first half" (Shaikh, 2018) [25]. 
"The impact of CBAHI accreditation on critical care unit outcome quality measures: a case study research paper revealed that there was no statistically significant difference between pretest and post-test results" (Shaikh, Al-Omari, A., \& Ahmed, 2018) [26].

"The Impact of Planetree Certification on a nationally and internationally Accredited Healthcare Facility and its Services research paper revealed that from July 2017 onwards, bedside shift report quality has been continuously improved, and by December 2017 , it reached to a well-established level of execution. The study hospital has managed to maintain well aligned policy and practice around family involvement and reached the expected quality level in October 2017. People in age groups $36-50$ and $51-65$ had an equal level of patient travel experience while $18-35$ and $66+$ age groups had an equal level of patient travel experience. However, $36-65$ aged people had better experience compared to 35 or younger and $66+$ ones. Respondents who came with their family had a better travel experience compared to who came alone or with a friend. Patient travel experience has gradually improved during July 2017 and March 2018 and shows a trend of improving further. Lab services viz. reception, lab staff, lab safety, did not show an increasing or decreasing trend during July 2017 and December 2017. Mainly laboratory services showed a lower level of quality during the above period. However, after implementing the Planetree certification standards in January 2018, lab services drastically improved. When it comes to employee experience, implementation of Planetree certification standards has resulted in a better employee experience" (Shaikh, AlOmari, \& Ahmed, 2018) [27].

2.7 Critical Analysis of healthcare accreditation standards:

Researchers had conducted several studies earlier to understand the variations in several national and international hospital accreditation standards.

"Critical Analysis of Patient and Family Education in JCI Accreditation and CBAHI Standards for Hospitals research paper revealed that the Patient and Family Education Standards in CBAHI Standards are very comprehensive, to the point and are much better than the JCI Accreditation" (Shaikh, Al-Towyan, \& Khan,
2016) [28].

"Critical Analysis of Staff Qualifications and Education Standards in JCI and Medical Staff \& Staffing Management Standards in DNV Accreditation for Hospitals research paper revealed that the SQE Standards in JCI Accreditation are very comprehensive, to the point and are much better than the DNV Accreditation" (Shaikh, Al-Towyan, \& Khan, 2016) [29].

"Critical Analysis of International Patient Safety Goals Standards in JCI Accreditation and CBAHI Standards for Hospitals research paper revealed that the IPSG Standards in JCI Accreditation are very comprehensive than CBAHI Standards" (Shaikh, Al-Towyan, \& Khan, 2016) [30].

"Critical Analysis of Patient and Family Rights in JCI Accreditation and CBAHI Standards for Hospitals research paper revealed that the PFR Standards in CBAHI Standards are very comprehensive than the JCI Accreditation standards" (Shaikh, 2017) [31].

2.8 Impact of hospital accreditation in other areas and processes:

"A Case Study on Electricity Consumption and Value Engineering in a Tertiary Care Hospital research paper revealed that the study hospital started to save Indian Rupees 30210 per month after the implementation of the first stage and Rupees 132810 after the implementation of stage II, and saved total of, Rupees 132,810 per month after the stage I and Stage II" (Shaikh, 2 019) [32].

"A Case Study on Recall of used Scopes in the Endoscopy Department by using a Failure Mode \& Effect Analysis (FMEA) Proactive Risk Management research paper revealed that the Risk Priority Number (RPN) which was 450 initially has decreased to 90 after implementing all the actions as listed in the FMEA. The occurrence score has decreased from 10 to 1 , detection from 5 to 10 and the Risk Priority Number (RPN) from 450 to 90 . However, the severity score remains the same" (Shaikh, 2020) [33].

"Religious and Cultural Aspects of Hand Hygiene in Healthcare Accreditations: A Review of Literature search study revealed that the community behaviour influences health care worker's professional behaviour has been supported by insufficient scientific facts until now. There are no data existing on the impact 
of religious customs on hand hygiene observance in health-care settings where religion is very deep-seated" (Shaikh, 2020) [34].

\section{CONCLUSION :}

The hospital accreditation has a positive impact on "Patients' Satisfaction" in the following Departments and Services: Ambulance, Physiotherapy, Dietary, Laboratory, Emergency, In-Patient Department, Haemodialysis, Radiology, Pharmacy and OutPatient Department Services. Also, the healthcare accreditation has a positive impact on the "Patients' Experience" in Ambulance Services, Hemodialysis Department Services and Emergency Department Services.

\section{DIRECTIONS FOR FUTURE RESEARCH :}

Further research is needed to understand the impact of accreditation in other areas of the hospitals.

\section{PRACTICE IMPLICATIONS :}

The healthcare providers should involve their patients to identify significant issues applicable to attributes of patient satisfaction in order to improve quality, patient safety and risk management.

\section{DISCLAIMER :}

This publication contains information obtained from authentic and highly regarded sources. Reasonable effort has been made to publish reliable data and information, but the author and the publisher cannot assume responsibility for the validity of all materials or for the consequences of the use.

All rights reserved. No part of this publication may be reproduced, stored in a retrieval system or transmitted, in any form, or by any means, electronic, mechanical, photocopying, recording or otherwise, without prior permission, in writing, from the publisher or the author.

\section{REFERENCES :}

[1] Lluis Bohigas et al. (1998). A comparative analysis of surveyors from six hospital accreditation programmes and a consideration of the related management issues. International Journal for Quality in Health Cane,10(1), 7-13.
[2] Montagu D. London: Department for international development health systems resource centre. Accreditation and other external quality assessment systems for healthcare: Review of experience and lessons learned. Working Paper.

[3] Shaw C. D. (2000). External quality mechanisms for health care: Summary of the ExPeRT project on visitatie, accreditation, EFQM and ISO assessment in European Union countries. External peer review techniques. European foundation for quality management. International organization for standardization. International Journal of Quality Health Care, 12, 169-75.

[4] Shaw C. D. (2004). Toolkit for Accreditation Programs. The International Society for Quality in Health Care. Australia, $1-67$.

[5] Brubakk et al. (2015). A systematic review of hospital accreditation: the challenges of measuring complex intervention effects. BMC Health Services Research, 15, 280.

[6] Ekram S, Rahman F. (2006). The concept of patient satisfaction as it relates to contemporary health care. TAJ, 19(1),

[7] Parasuraman, A Parsu \& Zeithaml, Valarie \& Berry, Leonard. (1988). SERVQUAL: A multiple- Item Scale for measuring consumer perceptions of service quality. Journal of retailing. 64(1), 12.

[8] Parasuraman, A., Zeithaml, V. A., \& Berry, L. L. (1985). A Conceptual Model of Service Quality and Its Implications for Future Research. Journal of Marketing, 49(4), 4150. https://doi.org/10.1177/0022242985049004 $\underline{03 .}$

[9] Michael Pulia, MD FAAEM (2011). Simple Tips to Improve Patient Satisfaction. American Academy of Emergency Medicine, 18(1):18-19.

[10] Shaikh, Z. M. (2016). The impact of hospital accreditation on the ambulance services satisfaction. International Journal of Emerging Research in Management \& Technology (IJERMT), 5(12), 76-84. http://doi.org/10.13140/RG.2.2.22367.76968.

[11] Shaikh, Z. (2017). The Impact of Hospital Accreditation on the Patient's 
Satisfaction of Physiotherapy Department Services. International Journal of Business, Management and Allied Sciences (IJBMAS), 4(4.2017), 143-154. http://doi.org/10.13140/RG.2.2.33967.64161.

[12] Shaikh, Z. M. (2017). The Impact of Hospital Accreditation on the Patients Satisfaction of Dietary Services. International Journal of Business, Management and Allied Sciences (IJBMAS), 4(4.2017), 1-12. http://doi.org/10.13140/RG.2.2.23409.79200.

[13] Shaikh, Z. M. (2017). The Impact of Hospital Accreditation on the Patients Satisfaction of Laboratory Department Services. International Journal of Business, Management and Allied Sciences (IJBMAS), 4(2.2017), 4277-4289. http://doi.org/10.13140/RG.2.2.10479.53926.

[14] Shaikh, Z. M. (2017). The Impact of Hospital Accreditation on the Patients Satisfaction of Emergency Department Services. International Journal of Business, Management and Allied Sciences (IJBMAS), 4(3.2017), 4330-4339.

http://doi.org/10.13140/RG.2.2.13834.98244.

[15] Shaikh, Z. M. (2017). The Impact of Hospital Accreditation on the Patient Satisfaction of In-Patient Department Services. International Journal of Emerging Research in Management \& Technology (IJERMT), 6(8), 368-383. http://doi.org/10.13140/RG.2.2.19299.04642.

[16] Shaikh, Z. M. (2017). The Impact of Hospital Accreditation on the Patients Satisfaction of Haemodialysis Department Services. International Journal of Emerging Research in Management \& Technology (IJERMT), 6(8), 384-392. http://doi.org/10.13140/RG.2.2.14818.02246.

[17] Shaikh, Z. M. (2017). The Impact of Hospital Accreditation on the Patients Satisfaction of Radiology Department Services. International Journal of Business, Management and Allied Sciences (IJBMAS), 4(1.2017), 4120-4130.

http://doi.org/10.13140/RG.2.2.26784.89606.

[18] Shaikh, Z. M. (2017). The Impact of Hospital Accreditation on the Patient's Satisfaction of Pharmacy Department Services. International Journal of Business,
Management and Allied Sciences, 4(4.2017), 189-199.

http://doi.org/10.13140/RG.2.2.35499.54566.

[19] Shaikh, Z. M. (2017). The Impact of Hospital Accreditation on the Patients Satisfaction of Out-Patient Department Services. International Journal of Business, Management and Allied Sciences (IJBMAS), 4(3.2017), 4384-4398. http://doi.org/10.13140/RG.2.2.17190.42561.

[20] Zuber Mujeeb Shaikh (2018). Impact of National Accreditation on the Patients' Experience of Ambulance Services: A Case Study. RESEARCH REVIEW International Journal of Multidisciplinary, 3(08), 177-181. http://doi.org/10.5281/zenodo.1341809.

[21] Zuber Mujeeb Shaikh. (2019). The Impact of Hospital Accreditation on the Patients' Experience of Hemodialysis Department: A Case Study. International Journal of Health Sciences and Pharmacy (IJHSP), 3(1), 31-39. DOI: https://doi.org/10.5281/zenodo.3237425.

[22] Zuber Mujeeb Shaikh. (2019). The Impact of Hospital Accreditation on the Patients' Experience of Emergency Department: A Case Study. RESEARCH REVIEW International Journal of Multidisciplinary, 4(2), 803-810. http://doi.org/10.5281/zenodo.2585955.

[23] Shaikh, Z. M. (2017). The Impact of Hospital Accreditation on the Completeness of Personnel Files in Human Resource Department. International Journal of Business, Management and Allied Sciences (IJBMAS), 4(4.2017), 236-244. http://doi.org/10.13140/RG.2.2.18868.14721.

[24] Shaikh, Z. M. (2018). The Impact of Hospital Accreditation on the Number of Occurrence Variance Report or Incident Reports. International Journal of Business, Management and Allied Sciences (IJBMAS), 5(1.2018), 1519.http://doi.org/10.13140/RG.2.2.27256.7552 $\underline{5 .}$

[25] Shaikh, Z. M. (2018). A Comparative Study on Laboratory and Blood Bank Performance by Using the Quality Indicators. International Journal of Business, Management and Allied Sciences 
(IJBMAS), 5(1.2018), $1-8$. http://doi.org/10.13140/RG.2.2.12850.30403.

[26] Shaikh, Z. M., Al-Omari, A., \& Ahmed, A. (2018). The impact of CBAHI accreditation on critical care unit outcome quality measures: a case study. IJHS, 8(7),394407.

http://doi.org/10.13140/RG.2.2.24226.12485.

[27] Shaikh, Z. M., Al-Omari, A., \& Ahmed, A. (2018). The Impact of Planetree Certification on a Nationally and Internationally Accredited Healthcare Facility and its Services. RESEARCH REVIEW International Journal of Multidisciplinary, 3(8), 318-332. http://doi.org/10.5281/zenodo.1344078.

[28] Shaikh, Z., Al-Towyan, S., \& Khan, G. (2016). Critical Analysis of Patient and Family Education in JCI Accreditation and CBAHI Standards for Hospitals. International Journal of Research in Business Management (IMPACT: $\quad$ IJRBM), 4(3), 29-38. http://doi.org/10.13140/RG.2.2.10414.00321.

[29] Shaikh, Z., Al-Towyan, S., \& Khan, G. (2016). Critical Analysis of Staff Qualifications and Education Standards in JCI and Medical Staff \& Staffing Management Standards in DNV Accreditation for Hospitals. International Journal of Research in Business Management (IMPACT: IJRBM), 4(3), 61-70. http://doi.org/10.13140/RG.2.2.17963.75044.

[30] Shaikh, Z., Al-Towyan, S., \& Khan, G. (2016). Critical Analysis of International Patient Safety Goals Standards in JCI Accreditation and CBAHI Standards for Hospitals. International Journal of Research in Business Management (IMPACT: IJRBM), 4(3), 71-78. http://doi.org/10.13140/RG.2.2.24674.63680.

[31] Shaikh, Zuber. (2017). Critical Analysis of Patient and Family Rights in JCI Accreditation and CBAHI Standards for
Hospitals. International Journal of Emerging Research in Management \& Technology (IJERMT), 6(7), 324-330. http://doi.org/10.13140/RG.2.2.15943.60323.

[32] Shaikh, Zuber Mujeeb. (2019).A Case Study on Electricity Consumption and Value EngineeringinaTertiaryCareHospital.Internatio nalJournalofHealthSciencesandPharmacy(IJH SP), 3(2), 11-15. DOI: https://doi.org/10.5281/zenodo.3411846.

[33] Shaikh, Zuber Mujeeb. (2020). A Case Study on Recall of used Scopes in the Endoscopy Department by using a Failure Mode \& Effect Analysis (FMEA) Proactive Risk Management. International Journal of Health Sciences and Pharmacy (IJHSP), 4(1), 13-24. DOI: http://doi.org/10.5281/zenodo.3766843.

[34] Shaikh, Zuber Mujeeb. (2020). Religious and Cultural Aspects of Hand Hygiene in Healthcare Accreditations: A Review of Literature. International Journal of Health Sciences and Pharmacy (IJHSP), 4(1), 40-48.

DOI: 